\title{
EVALUATION OF THE PERFORMANCE OF ROUTINE PHENOTYPIC METHODS FOR ACCURATE AND RAPID DETECTION OF CARBAPENEM- RESISTANT ENTEROBACTERIACEAE IN CLINICAL SAMPLES
}

\author{
Ayman A. Farrag ${ }^{1}$, Mohamed Ali Abdel-Rahman ${ }^{1}$, Amani El-Kholy ${ }^{2}$, and Arwa R. Elmanakhly, \\ Elsayed G.Salama ${ }^{1^{*}}$ \\ ${ }^{1}$ Botany and Microbiology Department, Faculty of Science (Boys), Al-Azhar University, P.N.:11884, \\ Nasr City, Cairo, Egypt \\ ${ }^{2}$ Department of Clinical Pathology, Faculty of Medicine, Cairo University, Cairo, Egypt \\ ${ }^{3}$ Microbiology and immunology Department, Faculty of pharmacy, Russian University in Cairo, \\ Egypt. \\ *Corresponding Author: SayedGama1999@gmail.com
}

\begin{abstract}
Resistance to carbapenems among Enterobacteriaceae has emerged as a global threat, because carbapenems are considered the most potent antimicrobials used for treatment of severe Gramnegative infections. This study aimed to compare between the phenotypic and genotypic methods used for detection of carbapenemase-producing clinical isolates of carbapenem resistant Enterobacteriaceae (CRE). We evaluated modified Hodge Test (MHT), EDTA-imipenem combined disc test and modified carbapenem inactivation method (mCIM) in comparison with the multiplex polymerase chain reaction (PCR) method (gold standard) for detection of carbapenemase activity of $65 \mathrm{CRE}$ isolates from patients admitted to a tertiary care hospital. The commonest source of CRE was blood culture (35\%). The most common CRE type was Klebsiella pneumoniae (90.7\%). The bacterial isolates resistant to meropenem, imepenem, amikacin and gentamicin were $98.64 \%, 97.94 \%, 94 \%$ and $93 \%$, respectively. Resistance of CRE to all classes of cephalosporin groups, quinolone and combination drugs was $100 \%$. On the other hand, CRE preserved $100 \%$ sensitivity to polymyxin-B and colistin. Out of $65 \mathrm{CRE}$ isolates, we detected bla $a_{\mathrm{OXA}-48}$ alone in $54 \%$, bla $a_{\mathrm{NDM}}$ alone in $22 \%$, bla $a_{\mathrm{KPC}}$ alone in $9.2 \%$ and coexistence of more than one gene in $14.5 \%$ of isolates, as $10 \%(7 / 65)$ of the isolates showed $\left(b l a_{\mathrm{OXA}-48}+\right.$ bla $\left._{\mathrm{NDM}}\right)$. While, $3 \%(2 / 65)$ have $\left(\right.$ bla $\left._{\mathrm{OXA}-48}+b l a_{\mathrm{KPC}}\right)$ and others $1.5 \%(1 / 65)$ have $\left(b l a_{\mathrm{NDM}}+b l a_{\mathrm{KPC}}\right)$. We didn't detect neither IMP nor VIM genes. Multiplex PCR was superior to phenotypic methods in detection and identification of carbapenemase genes. Among phenotypic methods, mCIM was the most sensitive for detection of carbapenemase production.
\end{abstract}

Keywords: Carbapenem-resistance; Enterobacteriaceae; API20E system; MALDI-TOF/MS; phenotypic and genotypic detection.

\section{INTRODUCTION}

Gram-negative bacteria represented as a common commensals in nature and cause infection in multiple body sites including the respiratory tract, bloodstream and urinary tract among others[1],even in some cases Gramnegative bacteria causes urogenital diseases, Farrag et al., reported that some parts of the world, oligospermia and azoospermia has been reported due to infection caused by Enterobacteriaceae include either cystourethritis, caused by trivial urinary bacteria or by sexually transmitted pathogens affecting fertility $[2,3]$.
Over the last decades, antimicrobial resistance emerged to a wide range of antibiotics [3]. Carbapenems possess broadspectrum antimicrobial activity and unique structure that provides protection against most $\beta$ lactamases such extended-spectrum $\beta$ lactamases, and hence are considered the most potent antimicrobial against Gram- negative infections [5]. Infection with carbapenemresistant Enterobacteriaceae (CRE) is considered as an urgent challenge in healthcare settings and a growing concern worldwide $[5,6]$. CRE have caused a broad range of nosocomial and/or community-acquired infections, for instance, urinary tract infections (UTI), 
pneumonia, bloodstream infections (BSI), intraabdominal infections (IAI), skin and soft tissue infections (SSTI), leading to high mortality and morbidity rates $[7,8,9]$.

Resistance to carbapenems among Enterobacteriaceae results from multiple mechanisms of resistance, including enzymatic inactivation, target-site mutation, and efflux pumps [5]. The recent emerging of Metallo- $\beta$ lactamases and other $\beta$-lactamases has hugely impacted the utility of carbapenems that considered the last resort antimicrobial agent [10]. A large variety of carbapenemases have been identified in Enterobacteriaceae belonging to three classes of $\beta$-lactamases: the Ambler classes A, B and D, some these classes are chromosomally encoded and others are plasmidencoded [11, 12, 13]. Moreover, the plasmidmediated resistance can spread among different bacterial isolates [5]. Therefore, highly sensitive and specific methods for identification of bacterial isolates and detection of carbapenemases in clinical laboratory settings are in demand $[14,15,16]$.

Phenotypic tests can initially predict the presence of carbapenemase production and are considered the easiest and most cost-effective methods, especially in limited laboratory setup, nevertheless they lack specificity regarding the type of carbapenemase being produced $[17,18]$.

Phenotypic assays depend on either growthbased assays such as modified Hodge test (MHT) and modified carbapenem inactivation method (mCIM) that have been proposed in CLSI (2017) guidelines [19,20,21] or hydrolysis methods which detect the product of hydrolysis that is catalyzed by carbapenemase enzymes such as Carba-NP and matrix-assisted laser desorption-ionization-time of flight mass spectrometry (MALDI-TOF MS) methods[22].

Molecular techniques have become an efficient tool for carbapenemase detection and characterization, and are currently considered to be the golden standard method. These are mostly focus on the detection of the carbapenem resistance genes in Enterobacteriaceae. More recently, multiplex PCR (Polymerase chain reactions) have been used for the detection of several classes of carbapenemases [5]. In Egypt, data on the mechanisms of carbapenemresistance among clinical isolates of Enterobacteriaceae and methods of their detection are sparse. Therefore, the aim of this study was to evaluate the sensitivity and specificity of three phenotypic methods, (MHT), (EDTAICDT) and (mCIM) in comparison with the PCR method in identification of 65 (CRE) isolates from patients admitted to a private tertiary care hospital.

\section{MATERIALS AND METHODS}

\section{1- Study design and sample collection}

A retrospective study conducted during period from April 2017 to April 2019, on patients hospitalized in the intensive care units (ICU) in private tertiary care hospital, and confirmed positive culture with CRE. All the cases enrolled in the study were cancer patients, hepatitis patients, urinary tract infection patient and blood stream infection patient. The clinical isolates were collected from blood, ascetic fluid, sputum, urine, drain, broncho-alveolar lavage and endotracheal tubes under complete aseptic conditions by physicians before administration of antibiotics. All the samples and samples from positive blood culture bottles also were recovered primary on both blood and MacConkey agar plates (Oxid Ltd. England). Then the plates were incubated at $37^{\circ} \mathrm{C}$ for 18 to $24 \mathrm{~h}$. Based on growth on MacConkey agar, isolates were identified as lactose fermenters appeared as pink colonies [23].

\section{2- Identification of bacterial isolates}

All isolates were identified with routine biochemical tests such as Triple sugar iron agar (TSI), Citrate utilization test (CIT), Urea agar test (UREA), Lysine iron agar (LIA), Motility/ Indole/ Ornithine media (MIO) all media mentioned above were obtained from Oxid Ltd. England except MIO which was obtained from $\mathrm{Hi}$ media India [24]. Identification was confirmed by The API 20E system for Enterobacteriaceae (Bio-Mérieux, Marcy l'Etoile, France) and (MALDI-TOF) mass spectrometry [25]

\section{3- Antibiotic susceptibility testing}

Susceptibility testing was done using a modified Kirby Bauer disc diffusion method on Muller Hinton agar (Oxoid Ltd) [26], and according to the guidelines of the Clinical and Laboratory Standards Institute (CLSI) [21]. A total of 15 types of antibiotic discs, were classified into 10 antimicrobial categories which 
were used: (Oxoid Ltd) penicillins (ampicillin $10 \mu \mathrm{g})$, one of the $\beta$-lactam $/ \beta$-lactamase inhibitors (amoxicillin /clavulanic acid $30 \mu \mathrm{g}$ ), monobactam (Aztreonam $30 \quad \mu \mathrm{g}$ ), antipsedumonal penicillins+ $\beta$-lactamase inhibitor (piperacillin/ tazobactam $110 \mu \mathrm{g}$ ), three of extended spectrum cephalosporins; $3^{\text {rd }}$ generations (ceftazidime, $30 \mu \mathrm{g}$; cefotaxime, 30 $\mu \mathrm{g}$; ceftriaxone, $30 \mu \mathrm{g}$ ), Extended spectrum cephalosporins; $4^{\text {th }}$ generations (cefepime 30 $\mu \mathrm{g}$ ), aminoglycosides (amikacin, $30 \mu \mathrm{g}$; gentamicin, $120 \mu \mathrm{g})$, floroquinolones (ciprofloxacin $5 \mu \mathrm{g}$ ), carbapenems (imipenem, $10 \mu \mathrm{g}$; meropenem, $10 \mu \mathrm{g}$ ), and cyclic polypeptide (tigecycline and polymyxin B), after overnight incubation at $37^{\circ} \mathrm{C}$. Isolates of Enterobacteriaceae which were resistant to either imipenem or meropenem or both, were selected for further phenotypic and molecular testing. Escherichia coli ATCC 25922 were used as a control strain.

\section{4- Phenotypic detection of carbapenemase activity}

Isolates that showed reduced susceptibility to carbapenem considered for further investigation of carpabenemase production by Modified Hodge test (MHT) that was performed according to CLSI guidelines [27], asthe clover leaf-like appearance between the test streaks near the disc was taken as positive for carbapenemase production. While the detection of MBLs (class B) was performed using a combined disk test of imipenem with EDTA (CDT-IMP+EDTA).A zone diameter difference of $>7 \mathrm{~mm}$ between imipenem disks and imipenem plus EDTA was interpreted as MBLpositive [28].and detection carpabenemase hydrolysis was performed using modified carbapenem inactivation method (mCIM) which determine either the meropenem had been hydrolyzed by carpabenemase activity (growth of an indicator organism close to the disk), or the meropenem is still active (appearance of large inhibition zone around the disk) [21].

\section{5- Genotypic analysis for carbapenemase encoded genes by Polymerase Chain Reaction (PCR)}

bla $_{\mathrm{VIM}}, b l a_{\mathrm{IMP}}, b l a_{\mathrm{KPC}}, b l a_{\mathrm{NDM}}$ and $b l a_{\mathrm{OXA}-48}$ genes were detected and amplified by a multiplex PCR assay according to (Poirel $\boldsymbol{e t}$ al).The design of the primers used for the detection of are given in Table (1) [29].

\section{6- Statistical Analysis}

IBM SPSS statistics (V. 26.0, IBM Corp., USA, 2019) was used for data analysis. Date were expressed as both number and percentage for categorized data.

The following tests were done:

1. Chi-square test to study the association between each 2 variables or comparison between 2 independent groups as regards the categorized data.

The probability of error at 0.05 was considered sig., while at 0.01 and 0.001 are highly sig.

2. Diagnostic validity test: It includes percent agreement between 2 items.

Table (1): Primer sequence used for carbapenemase encoded genes and their size.

\begin{tabular}{|c|c|c|c|}
\hline Target gene & Sequence $\left(5^{\prime}-3^{\prime}\right)$ & $\begin{array}{l}\text { Expected PCR } \\
\text { amplicon size (bp) }\end{array}$ & Reference \\
\hline bla OXA-48 & $\begin{array}{l}\text { F: 5' GCGTGGTTAAGGATGAACAC 3' } \\
\text { R: 5' CATCAAGTTCAACCCAACCG 3' }\end{array}$ & 438 & \multirow[t]{5}{*}{ Poirel et al, } \\
\hline bla $_{\mathrm{KPC}}$ & $\begin{array}{l}\mathbf{F}: 5^{\prime} \text { CGTCTAGTTCTGCTGTCTTG 3' } \\
\text { R: 5' CTTGTCATCCTTGTTAGGCG 3' }\end{array}$ & 798 & \\
\hline bla $_{\mathrm{NDM}}$ & $\begin{array}{l}\text { F: 5' GGTTTGGCGATCTGGTTTTC 3' } \\
\text { R: 5' CGGAATGGCTCATCACGATC3' }\end{array}$ & 621 & \\
\hline bla & $\begin{array}{l}\text { F: 5' GTTTGGTCGCATATCGCAAC 3' } \\
\text { R: 5' AATGCGCAGCACCAGGATAG 3' }\end{array}$ & 382 & \\
\hline $\boldsymbol{b l a}_{\mathrm{IPM}}$ & $\begin{array}{l}\text { F: 5'GCATAAGTCGCAATCCCCG 3' } \\
\text { R: 5'CTTCCTATCTCGACATGCCG 3' }\end{array}$ & 237 & \\
\hline
\end{tabular}




\section{RESULTS}

Out of 250 non duplicate enterobacterial isolates recovered from different clinical specimens during the study period $26 \%$ (65/250) were CRE. The types of specimens show the highest rate of CRE isolates was isolated from blood cultures $35.4 \%$ (23/65), followed by from endotracheal tube $21.5 \%(14 / 65)$, from sputum $20 \%$ (13/65), from urine $9 \%(6 / 65)$, and from wound swab $7.7 \%(5 / 65)$, from drain $3 \%(2 / 65)$, from ascetic fluid $1.5 \%(1 / 65)$ and from BAL $1.5 \%(1 / 65)$ as shown in Table (2).

Table (2): Distribution of the source specimens for CRE according to clinical samples

\begin{tabular}{|c|c|c|c|c|}
\hline & & & Total & $\begin{array}{l}\text { Probability } \\
\text { of error (P) }\end{array}$ \\
\hline \multirow[t]{16}{*}{ Specimen } & \multirow{2}{*}{$\begin{array}{l}\text { Ascetic } \\
\text { Fluid }\end{array}$} & Count & 1 & \multirow{18}{*}{$\begin{array}{l}\text { P-Value } \\
0.038\end{array}$} \\
\hline & & $\%$ & $1.5 \%$ & \\
\hline & \multirow[t]{2}{*}{ BAL } & Count & 1 & \\
\hline & & $\%$ & $1.5 \%$ & \\
\hline & \multirow[t]{2}{*}{ Blood } & Count & 23 & \\
\hline & & $\%$ & $35.4 \%$ & \\
\hline & \multirow[t]{2}{*}{ Drain } & Count & 2 & \\
\hline & & $\%$ & $3.1 \%$ & \\
\hline & \multirow[t]{2}{*}{ E.T.T } & Count & 14 & \\
\hline & & $\%$ & $21.5 \%$ & \\
\hline & \multirow[t]{2}{*}{ Sputum } & Count & 13 & \\
\hline & & $\%$ & $20.0 \%$ & \\
\hline & \multirow[t]{2}{*}{ Urine } & Count & 6 & \\
\hline & & $\%$ & $9.2 \%$ & \\
\hline & \multirow[t]{2}{*}{ W.S } & Count & 5 & \\
\hline & & $\%$ & $7.7 \%$ & \\
\hline \multirow{2}{*}{\multicolumn{2}{|c|}{ Total }} & Count & 65 & \\
\hline & & $\%$ & $100.0 \%$ & \\
\hline
\end{tabular}

* ETT, Endotracheal tube; W.S,Wound Swab.

\section{Identification of bacterial isolates}

The most common species were $K$. pneumoniae represented as $90.8 \%(59 / 65)$ followed by E. cloacae 4.6 (3/65), E.coli 3\% $(2 / 65)$ and $P$. vulgaris are 1.5(1/65) Table (3).
Table (3): The frequencies of isolated CRE species according to its species.

\begin{tabular}{|c|c|c|c|}
\hline \multicolumn{2}{|c|}{ organisms } & Total & $\begin{array}{l}\text { Probability of } \\
\text { error }(\mathrm{P})\end{array}$ \\
\hline \multirow{2}{*}{ E. cloacae } & Count & 3 & \multirow[t]{8}{*}{ P-Value (0.575) } \\
\hline & $\%$ & $4.6 \%$ & \\
\hline \multirow{2}{*}{ E.coli } & Count & 2 & \\
\hline & $\%$ & $3.1 \%$ & \\
\hline \multirow{2}{*}{ K. pneumoniae } & Count & 59 & \\
\hline & $\%$ & $90.8 \%$ & \\
\hline \multirow{2}{*}{ P. vulgaris } & Count & 1 & \\
\hline & $\%$ & $1.5 \%$ & \\
\hline \multirow[b]{2}{*}{ Total } & Count & 65 & \\
\hline & $\%$ & $\begin{array}{c}100.0 \\
\%\end{array}$ & \\
\hline
\end{tabular}

2. Antibiotic susceptibility testing by disc diffusion method:

The bacterial isolates resistant to meropenem and imepenem were $98.64 \%$ (64/65) and 97.94\% (63/65), respectively. Resistance to amikacin and gentamicin was 94\% (61/65) and 93\% (60/65) respectively. Resistance of CRE to all classes of cephalosporin groups, quinolone and combination drugs was $100 \%$. On the other hand, CRE preserved $100 \%$ sensitivity polymyxin-B and colistin.

\section{Phenotypic Detection of carbapenemase}

\subsection{Detection by the Modified Hodge test} (MHT).

Out of the 65 CRE isolates, $63.10 \%$ (41/65) were positive for MHT, of which $K$. pneumoniae was the most common carbapenemase producer as it constituted 56.9 $\%(37 / 65)$ of the total resistant CRE isolates, followed by $E$. cloacae that constituted $4.6 \%$ (3/65), E. coli constituted $1.5 \%(1 / 65)$ and $P$. vulgaris were Negative for MHT.

\subsection{Detection of potential Carbapenemases by EDTA-CDT}

Phenotypic detection of MBL was done by EDTA-CDT. Among the 65 isolates of CRE, $38.46 \%(25 / 65)$ were positive EDTA-CDT. Of which $33.8 \%(22 / 65)$ were $K$. pneumoniae, followed by $E$. coli at $3.0 \%(2 / 65)$ and $E$. cloacae at $1.5 \%$ (1/65), while P. vulgaris were negative for EDTA-CDT. 


\subsection{Detection by the modified carbapenem inactivation Method (mCIM)}

Our results show that $100 \%(65 / 65)$ of isolated CRE were positive mCIM. However, some CRE isolates gave positive results with more than one phenotypic method. 13.8\% (9/65) of CRE isolates gave positive result with (MHT+MBL+mCIM). Of which $10.7 \%(7 / 65)$ were $K$. pneumoniae , $1.5 \%(1 / 65)$ E. cloacae and $1.5 \%(1 / 65)$ were E.coli while $49.2 \%$ (32/65) of CRE isolates give positive result with (MHT + mCIM) of which $46.1 \%(30 / 65)$ were $K$. pneumoniae and $3.0 \%(2 / 65)$ were $E$. cloacae , and 24.6\% (16/65) of CRE isolates give positive result with (MBL+mCIM) of which $23.1 \%(15 / 65)$ were K. pneumoniae, and $1.5 \%$ (1/65) were E.coli. While the overall description of phenotypic methods used for detection of isolated CRE were shown in Figure (1).

\section{Genotypic detection of resistance genes}

Multiplex PCR was used for detection of most commonly carbapenemase encoding genes $b l a_{\mathrm{KPC}}$ for class A carbapenemase, (bla $a_{\mathrm{NDM}}$, $\left.b l a_{\mathrm{VIM}}, b l a_{\mathrm{IMP}}\right)$ for class B carbapenemases, and $b l a_{\text {OXA-48-Like }}$ for class D carbapenemases. All the 65 isolates showed presence of at least one of carbapenemase encoded genes by the multiplex PCR assay as showed in Figure (2).

As shown in Table (4), bla $a_{\text {OXA-48-Like }}$ gene was detected in $67.6 \%(44 / 65)$ of isolated CRE. K.pneumoniae were the major organism that harbored the bla $a_{\text {OXA-48-Like gene, which }}$ constituted $60 \%$ (39/65) followed by E. cloacae $4.6 \%(3 / 65)$, E.coli $1.5 \%(1 / 65)$, and $P$. vulgaris $1.5 \%$ (1/65). On the other hand, bla $a_{\mathrm{NDM}}$ gene was detected in $33.8 \%(22 / 65)$ of isolated CRE, K. pneumoniae showed $29.2 \%(19 / 65)$ followed by E. coli at $3.08 \%$ (2/65), E. cloacae at $1.54 \%(1 / 65)$, while $P$. vulgaris of isolated CRE were negative for $b l a_{\text {NDM }}$ genes. Besides this, bla $a_{\mathrm{KPC}}$ gene was detected in $13.8 \%(9 / 65)$ of isolated CRE; all of them were $K$. pneumoniae.

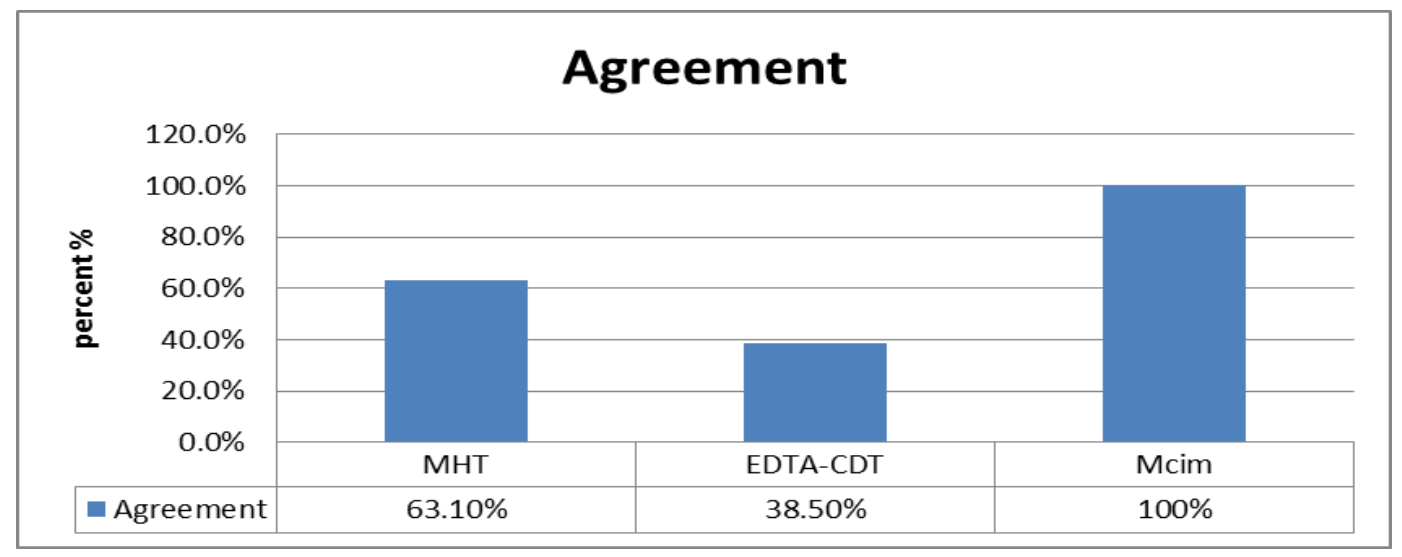

Figure (1): Percentage of phenotypic methods Agreement.

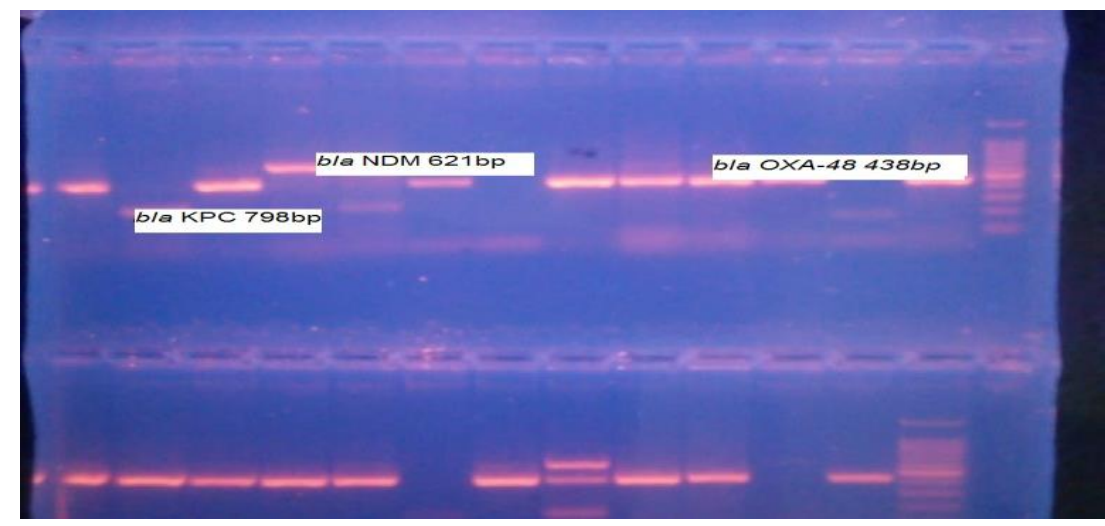

Figure (2): Multiplex PCR for detection of bla $\mathrm{OXA}_{\mathrm{N}-48,}$ bla $_{\mathrm{NDM}}$, and bla $_{\mathrm{KPC}}$ positive. 
Table (4): Frequencies of carbapenemase gene among isolated CRE.

\begin{tabular}{|l|l|l|l|}
\hline Bacterial isolate & \% bla $\mathrm{OxA48}$ & \% bla $\mathrm{NDM}$ & \% bla $\mathrm{KPC}$ \\
\hline K. pneumoniae & 60 & 29.23 & 13.85 \\
\hline E. cloacae. & 4.62 & 1.54 & 0 \\
\hline E. coli & 1.5 & 3.08 & 0 \\
\hline P. vulgaris & 1.5 & 0 & 0 \\
\hline Total & 67.69 & 33.85 & 13.85 \\
\hline
\end{tabular}

Out of 65 CRE strains included in the study some CRE isolates contain only one resistant gene as bla $a_{\mathrm{OXA}-48}$ alone $54 \%$ (35/65), bla $a_{\mathrm{NDM}}$ alone $22 \%(14 / 65)$ and $b l a_{\mathrm{KPC}}$ alone $9.2 \%$ (6/65). However, CRE showed coexistence of more than one carbapenemase gene as $10 \%$ $(7 / 65)$ of the isolates showed (bla $a_{\text {OXA-48 }}+$ bla $\left.a_{\mathrm{NDM}}\right)$, while $3 \%(2 / 65)$ have (bla $a_{\text {OXA-48 }}$ $\left.+b l a_{\mathrm{KPC}}\right)$ and others $1.5 \%(1 / 65)$ have $\left(b l a_{\mathrm{NDM}}\right.$ $\left.+b l a_{\mathrm{KPC}}\right)$.

\section{Evaluation of phenotypic methods for detection of carbapenemase genes}

The results showed that the MHT method is a good detector of bla $a_{\text {OXA-48 }}$ and bla KPC producing organisms. Of $44 \mathrm{CRE}$ isolates producing bla OXA-48, $77 \%$ (34/44) were detected by MHT. While from 9cases of bla kpc producing isolates MHT detected 89\% (8/9) of it. Also MHT detected only 18 (4/22) of CRE containing $b l a_{\mathrm{NDM}}$ genes. EDTA-CDT showed a notable detection rate of $b l a_{\text {NDM }}$ producing CRE isolates, out of 22 bla $a_{\mathrm{NDM}}$ CRE producers EDTA-CDT detected 91\%(20/22). While EDTA-CDT detecting 23\%(10/44) of CRE containing bla oxA-48 and detected $22.2 \%(2 / 9)$ of CRE containing bla кPC. On the other hand depending on mCIM for detection of carbapenanase, it was observed that mCIM detected carbapenamase in all isolated CRE which matching the results of the gold standard PCR method (100\%), as shown in (figure 3).

\section{DISCUSSIONS}

Infections caused by CRE are of particular concern [30]. These organisms are highly efficient at acquiring genes that code for mechanisms of antibiotic resistance, especially in the presence of antibiotic selection pressure. Furthermore, they contain a variety of resistance pathways, and often contain multiple mechanisms targeting the same antibiotic.

In the present study, 35.5\% (23/65) of CRE was isolated from blood specimens that represented the highest rate followed by endotracheal secretion 21.5\% (14/65); Sputum $20 \%(13 / 65)$ and urine $9.32 \%(6 / 65)$. Our findings are in accordance with Sood $\boldsymbol{e t}$ al, in which $25 \%(15 / 60)$ of the CER isolates were isolated from blood specimens, followed by endotracheal secretions $18.33 \%$ (11/60), sputum

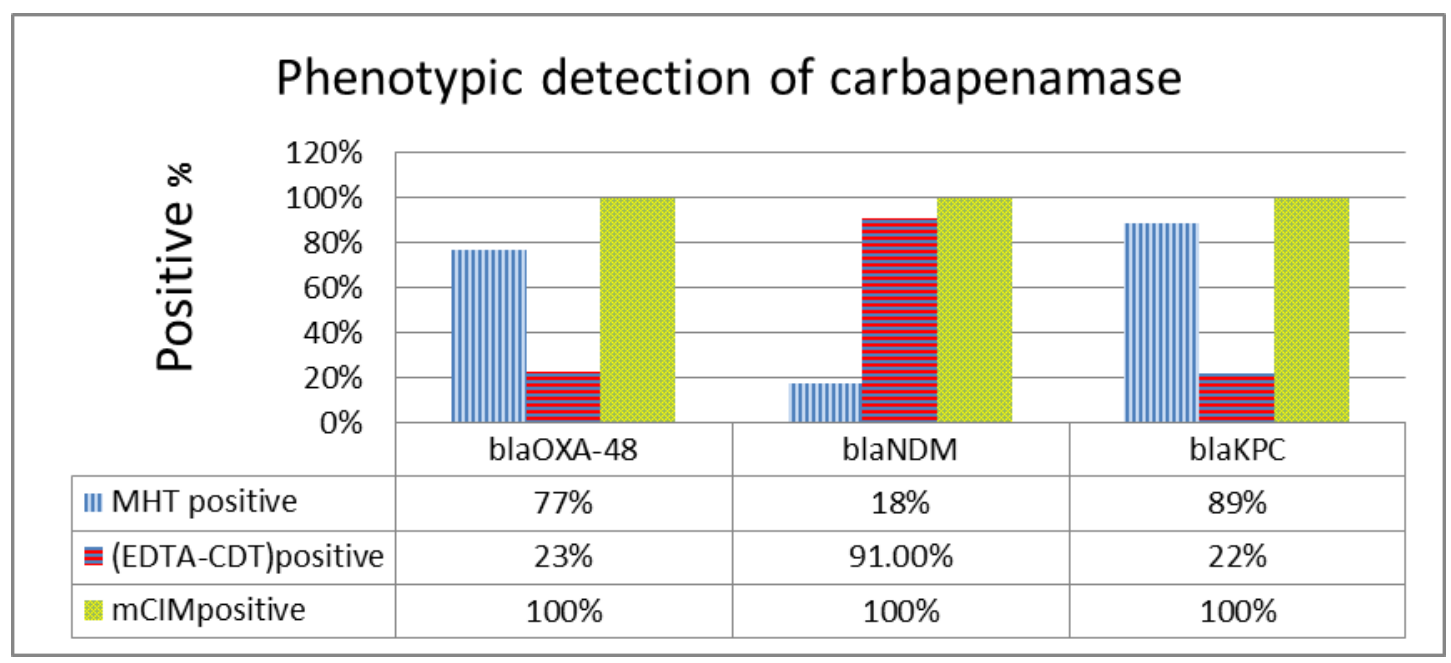

Figure (3): Relation of phenotypic methods to detect carbapenamase activity in relation to the type of carbapenemase genes. 
$11.66 \%$ (7/47) and 5\% (3/47) from urine [31]. On the other hand, Pawar et al., documented that urine samples were the leading specimen which contributed $48.2 \%$ (27/56) of CRE [17]. It is noteworthy to mention that many of the patients were immune compromised, hemato/oncology or bone marrow transplantation patients which related to utilization of intravascular devises and previous administration of antimicrobial agents.

In the present study carbapenem resistant $K$. pneumoniae represented $90.8 \% \quad(59 / 65)$, followed by E. cloacae, E. coli and P. vulgaris at $4.6 \%(3 / 65), 3.1 \%(2 / 65)$, and $1.5(1 / 65)$, respectively. Egyptian recent study done by Abdualall et.al, revealed that $K$. pneumoniae is the most common pathogen causing catheter related blood stream infection (47.4\%), followed by E. coli, E. cloacae, A. baumannii, and $P$. aeruginosa [32]. This is in keeping with recent reports that multidrug-resistant $K$. pneumoniae strains were a common colonizer in the hospital settings and main bloodstream infection pathogens in immunocompromised patients [33].

As regards susceptibility testing; $100 \%$ of the isolates showed sensitivity to colistin and polymixin-B which is consistent with the results of study reported from India by Sood et al. that reported100\% (60/60) sensitivities to colistin and polymyxin-B[31]. On the other hand, the present study showed relatively high resistant rates among amikacin and gentamicin $7.6 \%$ and $6.1 \%$ respectively; in addition, $100 \%$ of the isolates showed resistance to ciprofloxacin, cefotaxime, ceftazidime, cefotrixone, ampicillin, augmentin, piperacillin/tazobactam, Aztreonam, and cefepime. Obviously, the present study showed reduced susceptibility to commonly used antibiotics in the hospital settings due to lack of national antimicrobial stewardship program, misuse and overuse of antibiotics unrestricted empirical antimicrobial therapy and the inconsistency of implementation of national infection control guidelines [32,34].

Phenotypic tests, like the MHT is widely used in clinical laboratories as first-line phenotypic methods for detection of the carbapenemase-producing isolates [35]. The results of carbapenemase screening tests by MHT showed that $63.07 \%(41 / 65)$ of CRE isolates were positive; these result is relatively consistent with the recent study of Qadri $\boldsymbol{e t}$ al., who reported that out of the total $52 \mathrm{CRE}$ isolates, 67.3\%(35/52) were MHT positive[36].

In the present study, 38.4\% (25/65) showed positive result to EDTA-CDT. As well as, 91\% (20/22) of bla NDM producers showed positive results for EDTA-CDT. These results were in agreement with Pawar et al., who reported that $89 \%(59 / 66)$ of isolates were positive for EDTA-CDT and $82 \%$ (54/66) showed presence of bla $a_{\mathrm{NDM}-1}[17]$. However, EDTA-CDT couldn't detect $78 \%$ (7/9) of CRE that containing bla $a_{\mathrm{KPC}}$ and $77 \%(34 / 44)$ of $b l a_{\text {OXA-48 }}$ harboring. Accordingly, Chu et al., reported that MBL inhibitor (EDTA) may possess their own bactericidal activity, which may result in expanded inhibition zones not associated with true MBL production and hence false positive results occur. Also the false positive results may be due to increase outer membrane permeability caused by EDTA used in the test [9,37]. On the other hand, Picao et al., reported that falsenegative results might arise from carbapenem hydrolysis or inactivation caused by EDTA[38]. Franklin et al., showed that bla $a_{\mathrm{NDM}}$ gene is carried on plasmids which also carry a number of other genes conferring resistance to aminoglycosides, macrolides and sulphamethoxazole, thus making these isolates multidrug resistant [39].

In the present study the mCIM that is a new phenotypic method for detection of carbapenemases activity in CRE was positive in all 65 CP-CRE strains which is completely consistent to the result of Foldes $\boldsymbol{e t}$ al., where the mCIM was positive in all 19 CP-CRE strains and no false-positive results were noticed [40]. This is also relatively consistent to Pawar et al., who reported that only one isolate which was positive by PCR study was negative by mCIM method[17], making this new method most sensitive $(98.48 \%)$ among the phenotypic test studied. Pawar et al., shows that the only disadvantages of mCIM are its inability to discriminate the type of carbapenemase and it is time consuming [17].

However, the phenotypic tests have their own limitations, being time-consuming, difficult to interpret and unable to accurately differentiate between carbapenemases responsible for carbapenem resistance. This necessitated further testing by genotypic 
methods which can determine the most prevalent carbapenemase genes including five common and predominant carbapenemases genes $\left(b^{\prime} a_{\mathrm{KPC}}, b l a_{\mathrm{NDM}}, b l a_{\mathrm{OXA}-48-\mathrm{like}}, b l a_{\mathrm{VIM}}\right.$, and $\left.b l a_{\mathrm{IMP}}\right)$ in less than an hour.

Our study highlights that the most prevalent carbapenemase gene was bla $a_{\text {OXA-48-like }}$ at $67.7 \%$ $(44 / 65)$, while bla $a_{\mathrm{NDM}}$ represented $33.8 \%$ (22/65), bla KPC $_{14} \%$ (9/65), bla $a_{\mathrm{IMP}}$ and bla $a_{\mathrm{VIM}}$ genes were not detected. This is in keeping with a recent study by El-Kholy $\boldsymbol{e t} \boldsymbol{a l}$., who reported that bla OXA-48-like dominated (40.6\%), followed by $b l a_{\text {NDM-1 }}(23.7 \%)$ and $b l a_{\text {OXA-232 }}(4.5 \%)$ [41]. In contrast, Abdulall et al., showed that bla $a_{\mathrm{NDM}}$ as the predominant gene in $48.1 \%$ of $K$. pneumoniae, and in $14.3 \%$ of A. baumannii [32]. This is in agreement with previous studies that reported the predominance of bla $a_{\mathrm{NDM}}$ in Egypt and Middle East [33, 42, 43].

Our results showed the limited sensitivity of MHT in detection of carbapenem production, as it detected only $18 \%(4 / 22)$ for detection of $b l a_{\mathrm{NDM}}$ genes positive, $77 \%$ of $b l a_{\text {OXA-48-Like }}$ positive and $89 \%$ of $b l a_{\mathrm{KPC}}$ positive isolates. These results are in broad agreement with Doyle et al., results that MHT had the sensitivity of 98 $\%$ for detection of bla $a_{\mathrm{KPC}}$ harboring, $93 \%$ for

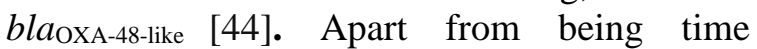
consuming, disadvantages of this test (MHT) include interpretation difficulties and the inability to distinguish between different classes of carbapenemases [45,46]. In recent Clinical Laboratory Standard Institute guidelines CLSI (2019), MHT is no longer included as a reliable phenotypic method for carbapenemase detection and other methods such as the CarbaNP test and the mCIM are more reliable [47]. CRE showed coexistence of more than one carbapenemase gene. This was in agreement with other Egyptian results [31,41,42]. Although, the distribution of the carbapenemase genes varied in different Egyptian studies, yet both NDM and OXA-48 genes were the most predominant.

\section{CONCLUSION}

Carbapenem resistance in Egypt is increasing, and OXA-48 is the most common source of carbapenem resistance in Enterobacteriaceae. Elderly population and ICU admission were important risk factors for CRE acquisition. Accurate detection of carbapenemase producing genes by molecular methods overcomes the problem related to CRE.
Though there is no signal method that is ideal for all situations, the mCIM method is simple, less subjective, cost effective, reproducible and most sensitive method for detection of CRE.

\section{REFERENCES.}

[1] Emily M E and Thaden T J. 2019.Epidemiology and Mechanisms Of Resistance Of Extensively Drug Resistant Gram-Negative Bacteria. Antibiotics 8 (2): 37.

[2] El-Shinnawy NA., Farrag AA., Saleh A K., Soliman N A., Ibrahim MM., and Abdel-Fattah Y R .2019. Wound Healing Potency Of Bacterial Cellulose Membranes Loaded With Different Antibiotics. Journal of Pharmaceutical, Biological and Chemical Sciences.10 (3): 360-376 .

[3] Farrag, A., M. Sherif, B. Harron, and A. Abo zaid. 2015. Evaluation of Escherichia coli Infection Control As The Most Prevalent Isolate Affecting Sperm Parameters. Al-Azhar Bulletin Of Science 26 (Issue 2-C): 25-36.

[4] Carlet J, Jarlier V, Harbarth S, Voss A, Goossens H, Pittet D, 2012. Participants of the $3^{\text {rd }}$ World Healthcare-Associated Infections Forum. Antimicrob Resist Infect Control.14; 1(1):11.

[5] Codjoe FS and Donkor ES. 2018. Carbapenem Resistance: A Review Med Sci (Basel); 6(1):1.

[6] Schwaber MJ, Carmeli Y JAMA. 2008. Carbapenem-resistant Enterobacteriaceae: a potential threat. 24; 300(24):2911-3.

[7] Wang JT, Wu UI, Lauderdale TL, Chen MC, Li SY, Hsu LY. 2015. Carbapenemnonsusceptible Enterobacteriaceae in Taiwan, PLoS One.10:e0121668.

[8] Hammoudi D, Ayoub Moubareck C, Aires J, Adaime A, Barakat A, Fayad N . 2014. Countrywide spread of OXA-48 carbapenemase in Lebanon: surveillance and genetic characterization of carbapenem-non-susceptible Enterobacteriaceae in 10 hospitals over a oneyear period. Int J Infect Dis. 29:139-44.

[9] Baran I and Aksu N. 2016. Phenotypic and Genotypic Characteristics of CarbapenemResistant Enterobacteriaceae in a Tertiary-Level Reference Hospital in Turkey.Annals of Clinical Microbiology and Antimicrobials 15 (1).

[10] Garcia M.M. 2013. Carbapenemases: A real threat. APUA News1; 31:4-6.

[11] AlTamimi M A, AlKhulaifi AM, and AlAjlan H. 2016.Comparison of Phenotypic and PCR Methods for Detection of Carbapenemases 
Production by Enterobacteriaceae. Saudi Journal of Biological Sciences 24 (1): 155-161.

[12] Miriagou V, Cornaglia G, Edelstein M, Galani I, Giske C, Gniadkowski M . 2010. Acquired carbapenemases in gramnegative bacterial pathogens: detection and surveillance issues. Clin. Microbiol. Infect. 16 (2), 112-122.

[13]Queenan, AM and Bush M K. 2007. Carbapenemases: the versatile- blactamases. Clinical Microbiology Reviews 20 (3): 440-458.

[14] Yamanda K, Kashiwa M, Arai K, Nagano N, Saito R. 2017. Evaluation of the modified carbapenem inactivation method and sodium mercaptoacetate-combination method for the detection of metallo- $\beta$-lactamase production by carbapenemase-producing Enterobacteriaceae. J Microbiol Meth; 132:112-115.

[15]- Lutgring JD, Limbago BM. 2016. The problem of carbapenemase_producing carbapenemresistant Enterobacteriaceae detection. J Clin Microbiol; 54:529-534.

[16] Butler W S, Abbott A. 2016. Is this the carbapenemase test we've been waiting for? A multi-center evaluation of the Modified Carbapenem Inactivation Method (mCIM). J Clin Microbiol; 55:2321-2333.

[17] Pawar S K, Mohite S T, Datkhile K D, Patil M N, Durgawale P, Patil S R. 2018. Closing the Gap Between Phenotypic and Genotypic Detection of Carbapenem Resistant Enterobacteriaceae by New Modified Carbapenem Inactivation Method. Journal of Clinical and Diagnostic Research, Nov, Vol12(11): DC01-DC04.

[18] Pragasa m AK, Veeraraghavan B, Bakthavatchalam YD, Gopi R, Aslam RF. 2017. Strengths and limitations of various screening methods for carbapenem-resistant Enterobacteriaceae including new method recommended by clinical and laboratory standards institute: A tertiary care experience. Indian J Med Microbiol.35(1):116-19.

[19] Andre B, Philippe B, Nathalie G, Catherine D, Dominique D, Guillaume A, et al. 2012. Phenotypic screening of carbapenemases and associated $\beta$-lactamases in carbapenem-resistant enterobacteriaceae. J Clin Microbiol; 50(4):1295-302.

[20] Datta P, Gupta V, Garg S, Chander J. 2012. Phenotypic method for differentiation of carbapenemases in Enterobacteriaceae. Study from north India. Indian J Pathol Microbiol; 55:357-60.
[21] Clinical and Laboratory Standards Institute. 2017. Performance standards for antimicrobial susceptibility testing, 27th ed. CLSI supplement M100. Clinical and Laboratory Standards Institute, Wayne, PA.

[22] Zimmermann, S. 2015. Maldi-ToF. In: "Modern Techniques for Pathogen Detection", Popp, J., M. Bauer (Ed.), pp. 221-254. Wiley Blackwell, Weinheim, Germany.

[23] Tille PM. Bailey \& Scott's Diagnostic Microbiology (2013).13th edition. Philadelphia, PA, USA: Mosby Elsevier.

[24] Dortet L, Poirel L, Nordmann P. 2012. Rapid identification of carbapenemase types in Enterobacteriaceae and Pseudomonas spp. by using a biochemical test. Antimicrob Agents Chemother; 56:6437-40.

[25] Seng P, Drancourt M, Gouriet F, La Scola B, Fournier PE, Rolain JM, Raoult D .2009. Ongoing revolution in bacteriology: routine identification of bacteria by matrix-assisted laser desorption ionization time-of-flight mass spectrometry. Clin. Infect. Dis. 49(4):552-553.

[26] Bonev B, Hooper J, Parisot J. 2008. Principles of assessing bacterial susceptibility to antibiotics using the agar diffusion method. J Antimicrob Chemother;61:1295-301.

[27] CLSI. 2015. Performance Standards for Antimicrobial Susceptibility Testing; Twentyfive Informational Supplement. CLSI document M100-S25. Wayne, PA: Clinical and Laboratory Standards Institute.

[28] Pournaras S, Poulou A, Voulgari E, Vrioni G, Kristo I, Tsakris A. 2010. Detection of the new metallo-beta-lactamase VIM-19 along with KPC-2, CMY-2 and CTX-M-15 in Klebsiella pneumoniae. $\mathrm{J}$. Antimicrob. Chemother. 65:1604-1607.

[29] Poirel, L.; Ros, A.; Carrër, A.; Fortineau, N.; Carricajo, A.; Berthelot, P.; Nordmann, P. 2011. Cross-border transmission of OXA-48producing Enterobacter cloacae from Morocco to France. J. Antimicrob. Chemother. 66, 11811182.

[30] Asem M, Abdalla MN, Elsherif R, Saad A, Kadry ID, Hasanin A, Bassyouni R, Hussein Gomaa MS. 2017.Emergence of Gram-Negative Bacilli with Concomitant blaNDM-1and blaOXA-48-Like Genes in Egypt. American Journal of Internal Medicine; 5(1): 1-6.

[31] Sood, Smita. 2014. "Identification And Differentiation Of Carbapenemases In Klebsiella Pneumoniae: A Phenotypic Test 
$\begin{array}{lccr}\text { Evaluation Study } & \text { From } & \text { Jaipur, } \\ \text { India". JOURNAL OF } & \text { CLINICAL } & \text { AND } \\ \text { DIAGNOSTIC RESEARCH;7027.4614. } & \end{array}$

[32] Abdulall AK, Tawfick MM, El Manakhly AR, El-KholyA (2018) Carbapenem-resistant Gramnegative bacteria associated with catheterrelated bloodstream infections in three intensive care units in Egypt. Eur J Clin Microbiol Infect Dis 37(9):1647-1652.

[33] Satlin MJ, Jenkins SJ, And Walsh TJ.2014. The global challenge of carbapenem-resistant enterobacteriaceae in transplant recipients and patients with hematologic malignancies. Clin Infect Dis 58(9):1274-1283.

[34] Talaat M, Saied T, Kandeel A, El-Ata GA, ElKholy A .2014.A point prevalence survey of antibiotic use in 18 hospitals in Egypt. Antibiotics 3:450-460.

[35] Pasteran, F., Mendez, T., Rapoport, M . 2010. Controlling false-positive results obtained with the Hodge and Masuda assays for detection of class A carbapenemase in species of Enterobacteriaceae by incorporating boronic acid. J. Clin. Microbiol.,48: 1323.

[36] Qadri R, Suhail A, Dalip K K, Gulnaz B, and Bashir F. 2019.Detection Of Carbapenem Resistant Enterobacteriaecae and The Comparison Between Phenotypic Methods And Multiplex PCR". Indian Journal of Microbiology Research 6 (2):126-130.

[37] Chu Y W, Cheung TK, Ngan JY, and Kam KM. 2005. EDTA susceptibility leading to false detection of metallo-beta-lactamase in Pseudomonas aeruginosa by Etest and an imipenem-EDTA disk method. Int. J. Antimicrob. Agents 26:340-341. Clin Infect Dis;49:271-4.

[38] Picao RC, Andrade SS, Nicoletti AG, Campana EH, Moraes GC, Mendes RE, Gales AC.2008.Metallo-ß-Lactamase Detection: Comparative Evaluation of Double Disk Synergy versus Combined Disk Tests for IMP-, GIM-, SIM-, SPM-, or VIM- Producing Isolates. J. Clin. Microbiol. 46(6):2028-2037.

[39] Franklin C, Liolios L, Peleg Ay.2006. Phenotypic detection of carbapenem susceptible metallo- $\beta$-lactamase producing Gram negative bacilli in the clinical laboratory. J. Clin. Microbiol. 44:3139-3144.
[40] Földes A, Doina-Veronica B, and Edit S. 2018. Phenotypic And Molecular Identification Of Carbapenemase-Producing Enterobacteriaceae Challenges In Diagnosis And Treatment. Revista Romana De Medicina De Laborator 26 (2): 221-230.

[41] El-Kholy AA, Girgis SA, Shetta MAF. 2020. Molecular characterization of multidrugresistant Gram-negative pathogens in three tertiary hospitals in Cairo, Egypt. Eur J Clin Microbiol Infect Dis.

[42] Amer WH, Khalil HS, Abd ELWahab MAA. 2016. Risk factors, phenotypic and genotypic characterization of carbapenem resistant Enterobacteriaceae in Tanta University Hospitals, Egypt. Int J Infect Control v12:i2.

[43] Shibl A, Al-Agamy A, Memish Z, Senok A, Abdul Khader S, Assiri A et al . 2013. The emergence of OXA-48- and NDM-1- positive Klebsiella pneumoniae in Riyadh, Saudi Arabia. Int J Infect Dis 17(12):1130-1133.

[44] Doyle D, Peirano G, Lascols C, Lloyd T, Church DL, Pitout JD. 2012. Laboratory detection of Enterobacteriaceae that produce carbapenemases. J Clin Microbiol; 50:3877-80.

[45] Hirsch, E.B., Tam, V.H. 2010. Detection and treatment options for Klebsiella pneumonia carbapenemases (KPCs): an emerging cause of multidrug-resistant infection. J. Antimicrob. Chemother., 48: 1323-1332.

[46] Tsakris, A., Kristo, I., Poulou, A., et al. 2009. Evalution of boronic acid disk tests for differentiating KPC-possessing Klebsiella pneumoniae isolates in the clinical laboratory. $J$. Clin. Microbiol., 47: 362-7.

[47] Clinical and Laboratory Standards Institute. (CLSI, 2019) Performance standards for antimicrobial susceptibility testing: $2^{\text {th }}$ informational supplement. CLSI publication 2019; M100-S29. Clinical and Laboratory Standard Institute, Wayne, Pennsylvania. 


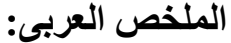

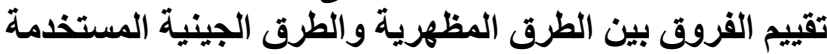 \\ للكثف عن البكتريا المعوية الممرضة المرية المقاومة للكاربابينيم.}

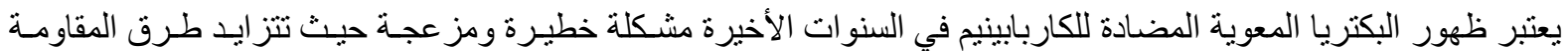

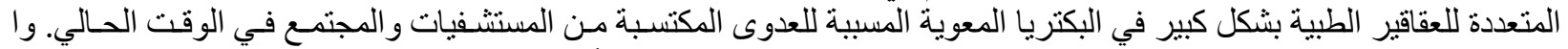

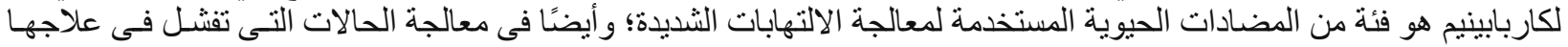

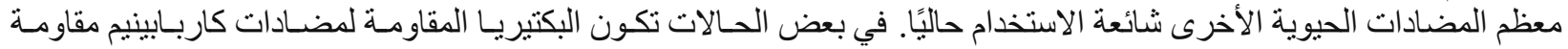

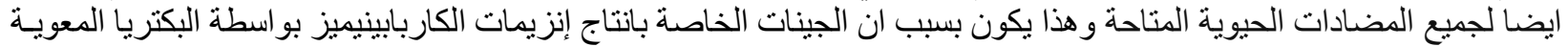

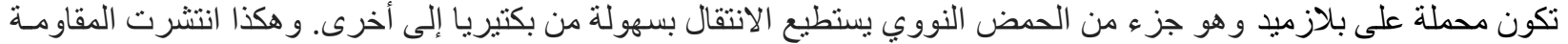

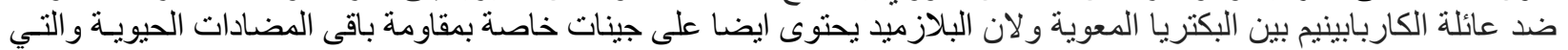

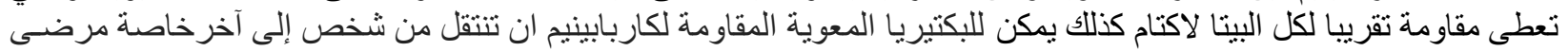

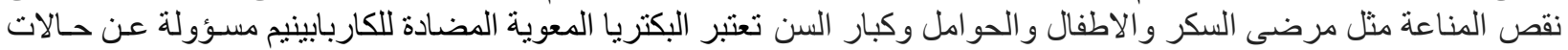

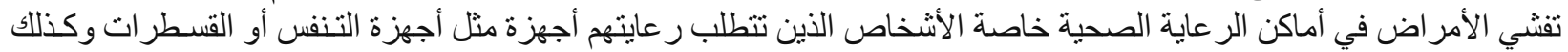

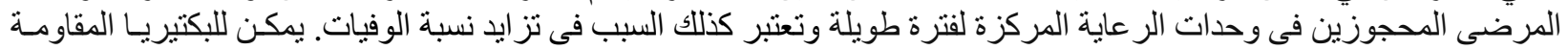

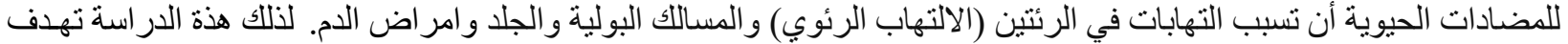

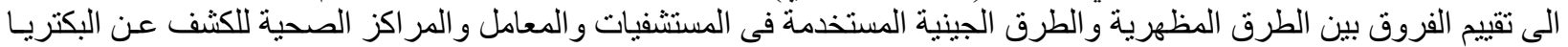

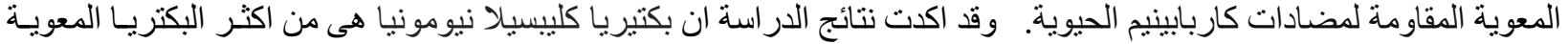

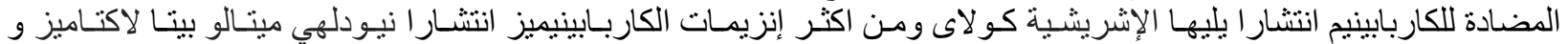

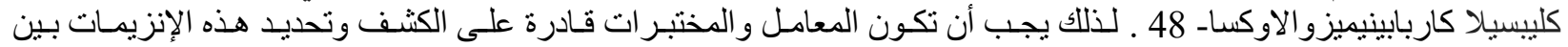

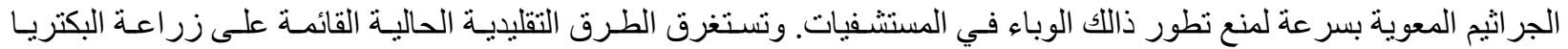

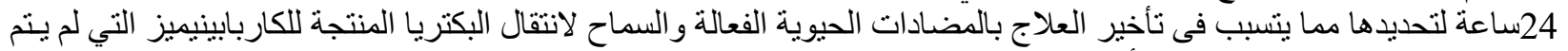

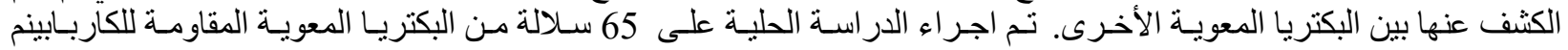

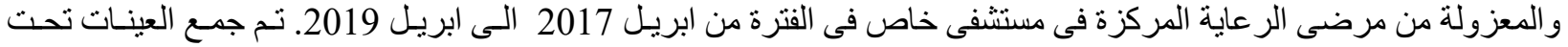

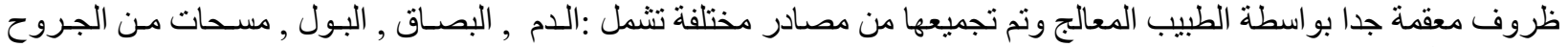

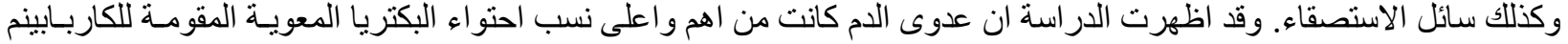

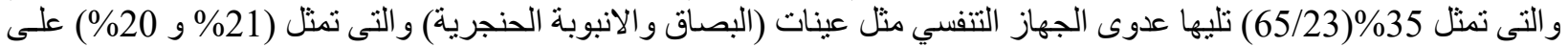

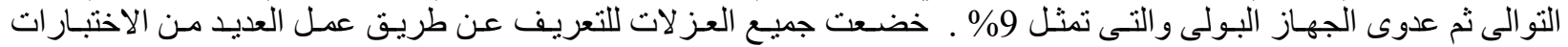

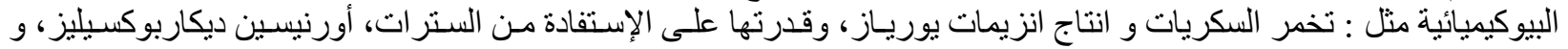

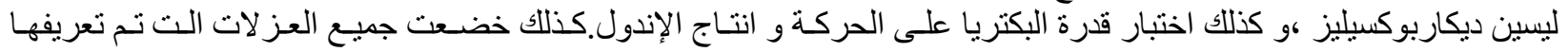

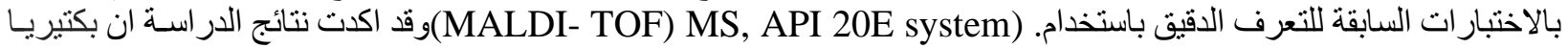

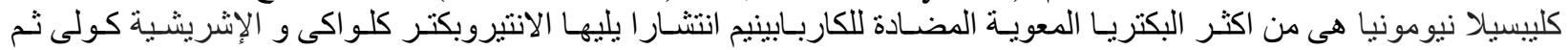

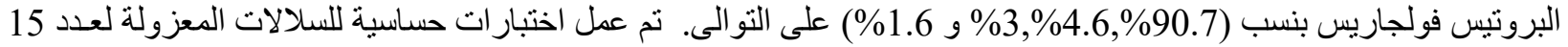

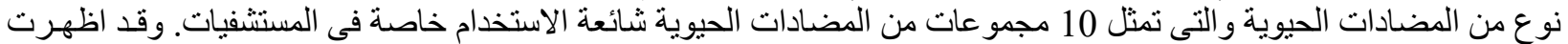

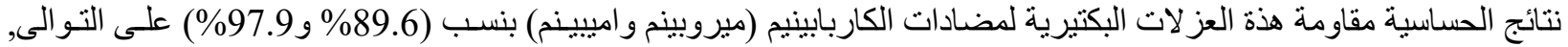

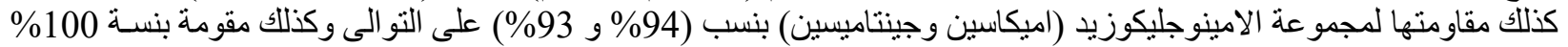

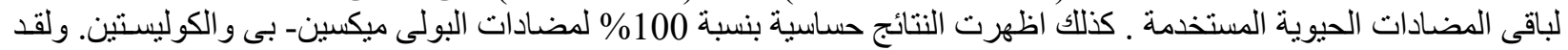

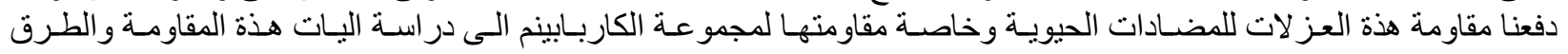

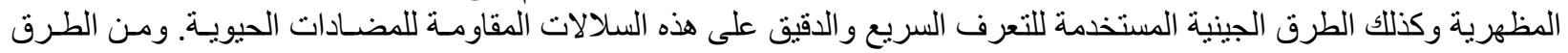

